great, shock. The extreme diameter of the seismic area did not materially exceed $35^{\circ}$ miles, and making every allowance, the area over which the shock might have been felt-including in this the sea-could not have been more than 95,000 square miles; in the Californian earthquake of 1906, the corresponding figure was 372,500 , and in the Indian earthquake of 1897 it was $1,750,000$. These figures give some idea of the relative magnitude of the three earthquakes, and in the present state of the science it does not seem possible to find a more satisfactory means of comparison.

A point which has attracted notice, and is worthy of attention, is the peculiar weather which accompanied and followed the earthquake. We need not consider the fact that it coincided with the sudden break-up of an equally sudden and severe frost over northern Europe, nor the unusual cold and snowstorms which have followed it in southern Italy. These were due to meteorological conditions of great extent, in all probability unconnected with, and independent of, the earthquake, but the sudden fog which, according to every account, settled on the Straits of Messina stands in a different case. The earthquake in Mexico of January 24, I898, was similarly followed by a heavy mist, at a time of year when mists are usually unknown, and rainfall is so frequently reported as the immediate successor of an earthquake that we can no longer reject the hypothesis of a real connection between the two. Earthquake weather is a common expression in earthquake countries, but is usually applied to a heavy and oppressive feeling in the air which is supposed to precede an earthquake. $\mathrm{Mr}$. Maxwell Hall has attempted to find an explanation in alterations of the barometric gradient by rapid upheaval of the ground, and has shown that uplifts, which are within the range of possibility, would produce the required effects, but whether there is, or is not, an earthquake weather, in the ordinary sense of the words, there seems reason for believing that in another sense they represent a reality, and that, as has been suggested by Prof. Milne, the disturbance of the ground, when transmitted to the overlying air, may determine precipitation, and explain the apparent association of severe earthquakes with mist and rain. What may be the nature of the influence we know not, but if mechanical, it must be either the result of the vibratory motion of the ground, or else of permanent changes of level, accompanied by the sudden upheaval or depression of the overlying column of air, and of this permanent change of level we are still without any satisfactory evidence. In the accounts which have reached us, quays and pierheads are mentioned as having subsided beneath the water, but there is nothing to show that more than a settlement of made ground has taken place, while the photographs which have been published suggest that this rather than any displacement of the solid ground is the explanation of the apparent subsidence, and the commission appointed to inquire into the changes which have taken place in the harbour of Messina has reported that though the quays have been destroyed in places, no permanent change has taken place which will interfere with the continuation of its use as a port.

R. D. O.

\section{GRAVITATIONAL THEORIES.}

$\mathrm{T}$ is well known how cultivators of physical science in Great Britain lag behind the most up-to-date philosophical views in continuing to think that valuable light is thrown on physical phenomena by the elaboration and study of mechanical analogies of more familiar type, and more readily grasped by the mind.
These matters are, perhaps unfortunately, for us largely the affair of specialists in science, who understand both the value and the limitation of the method.

For example, in the days of the very instructiveand somewhat insular-mathematical development of Lord Kelvin's idea of vortex atoms, the mechanical analogies of gravitation were much to the fore; and in particular Prof. W. M. Hicks elaborated, a quarter of a century ago (e.g. in Camb. Phil. Soc. Proc., October, I879), on the basis of experiments by Guthrie and others, a beautiful theory of how the attractions of gravitation could be imitated by pulsating bodies in a liquid medium. Further developments, theoretical and experimental, of interesting character, with relation also to electrodynamics, were made in the well known experiments of Bjerknes. Indeed, some such notion is the only simple direct mode of imitating gravitation which has presented itself; there is the alternative, of course, that it may be a residual of other more potent actions.

In this regard, the pulsation analogy lies at the back of the heads of most people interested in the subject. But lest we forget, the watchful enterprise of the daily Press in reporting by special correspondence from Berlin the recent exciting revival of these ideas illustrates one of the ways in which it can keep us in touch with the latest developments of science. Doubtless the experimental phenomena reported with so much emphasis will be found eventually to contain much that is interesting and useful as new aspects of this well-worn subject.

\section{MOUNTAINEERING IN NORTHERN} NORWAY.'

THERE being little left in Switzerland for the mountaineering pioneer, climbers whe prefer exploration to gymnastics have been driven further afield. Mrs. le Blond (then Mrs. Fred Burnaby) was one of the leaders in Swiss winter climbing; but after fifteen seasons in the Alps she was induced to visit northern Norway, partly from the desire for virgin peaks and partly to give her well-known guide, Imboden of St. Nicholas, a change of scene after the death of his son on the Lyskamm. This volume records the story of five seasons' climbing amongst the glaciers and peaks of northern Norway near Tromso. The narrative is pleasantly and modestly written, and is occupied by short accounts of the author's twenty-seven first ascents in this district. The country has many advantages over Switzerland; it has the charms of solitude, of freedom, and of being imperfectly mapped and explored; until recently its peaks were unclimbed, and many of them even unnamed.

Mountaineering in northern Norway is free from two Alpine risks. No one can be benighted in this land of continuous daylight, and there is no danger from exposure to cold in the mild climate, repeatedly attributed by Mrs. le Blond to the Gulf Stream, in which her faith is firm and primitive. The country has, however, the drawbacks of long spells of bad weather. On one occasion, for example, two friends arrived at Mrs. le Blond's camp for a few weeks' climbing at the beginning of " five weeks of the very worst weather I have ever seen "' (p. I79). The constant mists and clouds add greatly to the picturesqueness of the country, and to them are due the beauty of many of Mrs. le Blond's photographs; but fogs and continual rain may easily prevent any mountaineering except to those who have most of

1 " Mountaineering in the Land of the Midnight Sun." By Mrs. Aubrey le Blond. Pp. xii $+3 \mathrm{C}_{4}$; map and $7 x$ illustrations. (London: T. Fisher Unwin, 1908.) Price tos. $6 d$. net.

No. 2048, VOL. 79] 
the season at their disposal. The mosquitoes do their best to render life intolerable, but Mrs. le Blond found them of no trouble except in the valley; the writer, however, remembers one easy rock-climb in an area to the south of Mrs. le Blond's district that became dangerous owing to a flight of mosquitoes, which took advantage of the shelter from the wind to accompany him up the cliff.

The extreme rottenness of the rocks renders the danger of falling stones greater than in Switzerland. The mountains are covered with such a litter of loose stones that, according to the author, it is unsafe for more than three climbers to go on a rope. "Dumkopf ! you will have the whole mountain down," is one of Imboden's ejaculations to his son. Mrs. le Blond seems disposed to attribute the superior security of the Alpine rocks to successive climbers having cleared away the loose material. Her testimony throughout the book to the looseness of the rocks, in the book is its fine series of photographs; the 304 pages of the text are illustrated by seventy photo $\rightarrow$ raphs, nearly all of which occupy a full page, and the illustrations give an excellent idea of the geographical structure of the country. Some of them confirm the view that this part of Norway is a dissected plateau. The book has, unfortunately, no index and practically no map, for its useless chart of Scandinavia and the Baltic merely indicates the position of the district in which Mrs. le Blond's mountaineering feats were achieved.

\section{J. W. G.}

\section{A NATIONAL SCHEME OF AFFORESTATION}

THE Royal Commission on Coast Erosion and 1 Afforestation has issued its second report, which deals with afforestation. If the scheme proposed in this report be adopted, it would mean that in eighty

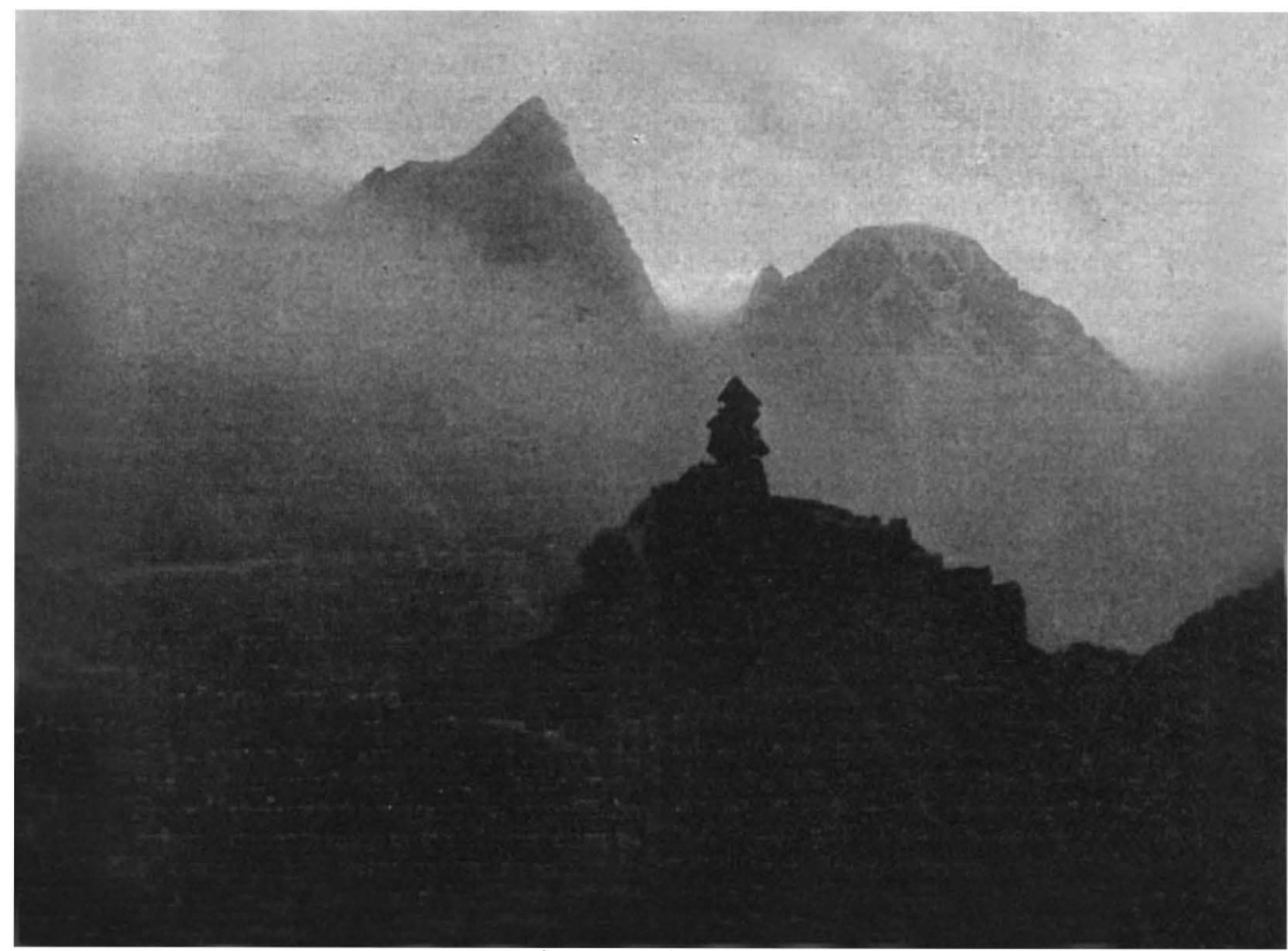

The Urtind at Midnight. In the background the Faestning and Kjostind. From "Mountaineering in the Land of the Midnight Sun."

and the photographs showing the sharp cones and jagged pinnacles characteristic of the country, suggest that only the lower slopes of the mountains have been glaciated. She speaks of well-rounded glaciated surfaces on the lower ground, and it appears possible, from her descriptions and photographs, that, as has long been well known regarding the Lofoden Islands, the mountains were never completely buried beneath an ice-sheet. Their upper slopes may still wear the débris due to pre-Glacial weathering.

The book gives very little direct geographical information other than details as to the climbing. To mountaineers in the Tromso district it will be indispensable. There is a short chapter on the Lapps, and much enthusiasm expressed for both Norway and the people. One of the most valuable features No. 2048, VOL. 79] years from its commencement there would be afforested 9,000,000 acres of land at present classed in the agricultural returns as rough mountain land used for grazing. In their investigations the commissioners find that there are no less than $16,000,000$ acres not under cultivation or permanent pasture in Great Britain. To this there may be added several million acres of similar land in lreland. However, much of this land is not suitable even for tree-growth, and may be already used to better advantage. The commissioners find $9,000,000$ acres of this land is suitable for afforestation, and they recommend that the State should undertake the task of afforesting that area.

Two schemes, a larger one and a smaller one, are proposed:-First, that the maximum area-9,000,000 acres-should be planted up at the rate of $\mathrm{I}_{50}, 000$ 